\title{
A Brighton Journal
}

Isabelle Sutton

Freelance translator, Montreal, Canada

I was born in South London, moved to Brighton at a very young age, and then left for France with my mother and siblings at the age of 7 . So when people ask me where I come from, I struggle to give a straightforward answer. There is however one place that feels like home to me: Brighton, the town I have always gone back to since I was a child, to visit my father, work a summer job or (mostly) have a good time. We lived in this house on Franklin Road when I was a child, then it was sold to family friends and later bought back by my step-mother who still owns it to this day. The picture of the front door, in all its simplicity, evokes so many memories of being home. Over the years, the smell and feeling I get walking into the house have remained the same, evoking comfort and warmth.

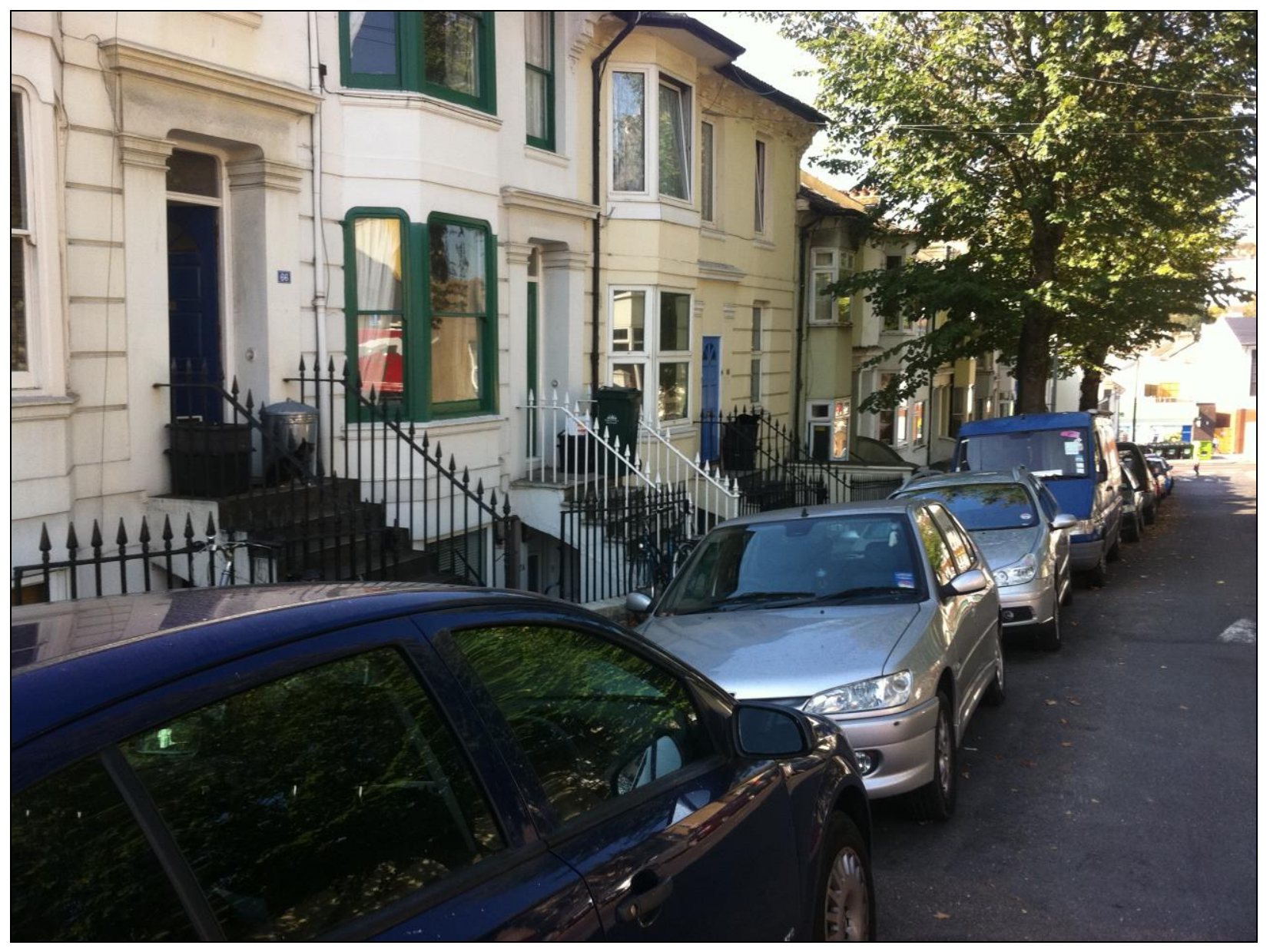

Photo credit: Isabelle Sutton 

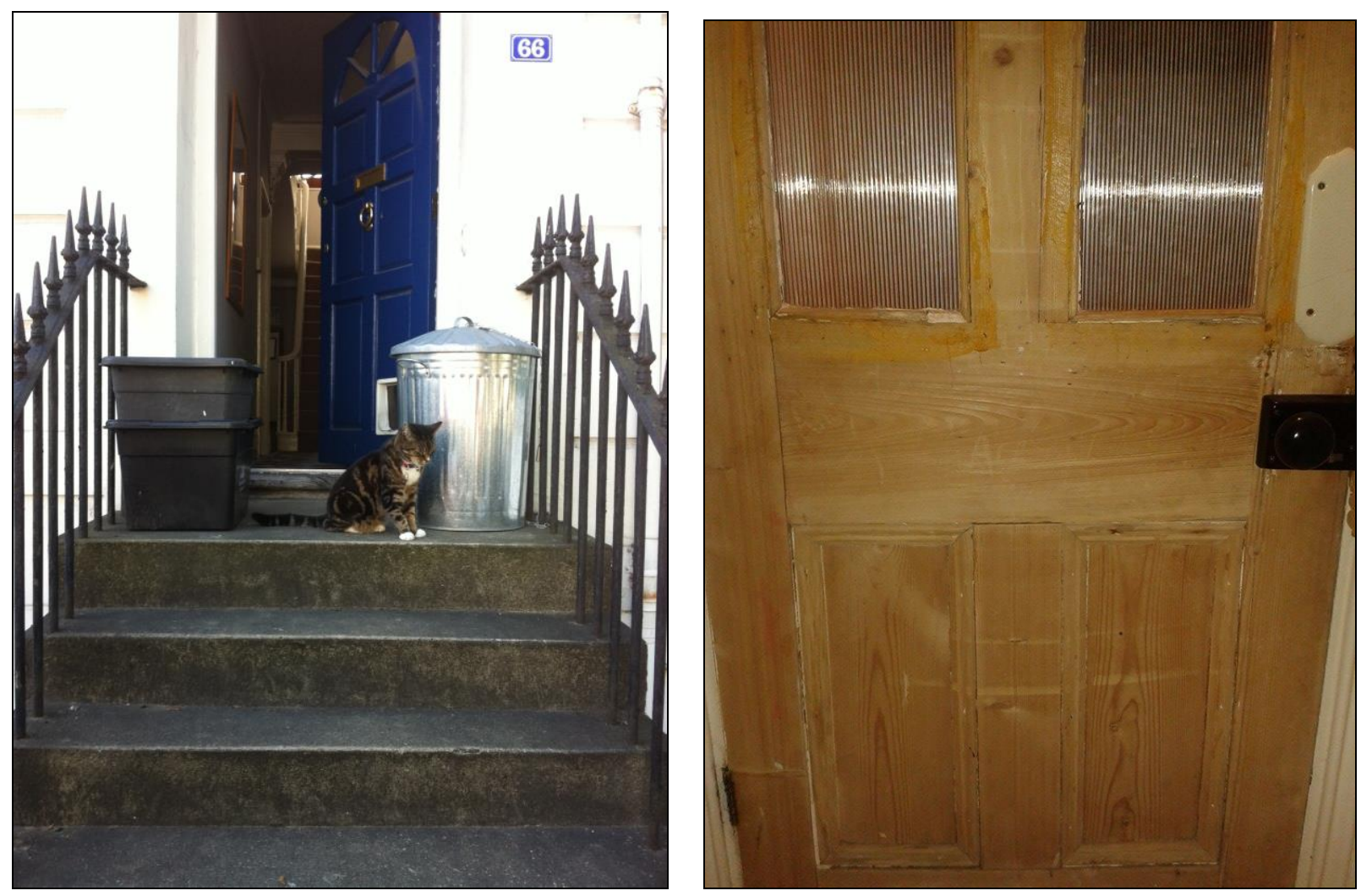

Photo credit: Isabelle Sutton

There is a funny story behind the picture of the wooden door, which is the toilet door. In the 90s, my sister and I were huge fans of the Swedish pop band Ace of Base. One day, my dad and step-mother found the words "Ace of Base" carved onto the door. They were not happy, and for years my sister and I denied being the culprit. This photo was taken during my last visit, approximately 20 years later, and although it is not clearly visible, if you look closely, you can still see it a little (especially the first letter "A"). Although the house has been renovated, the door has been left untouched. The funny part (or scary part) is that today both my sister and I think we were the one who did it. I have no idea if it is my mind playing tricks on me, but in my memory, I am the one who wrote it! My sister would tell you the exact same thing, that she wrote it. Go figure. It definitely is intriguing in the context of "memory"... 
TranscUlturAl, vol. 8.1 (2016), 113-120.

http://ejournals.library.ualberta.ca/index.php/TC

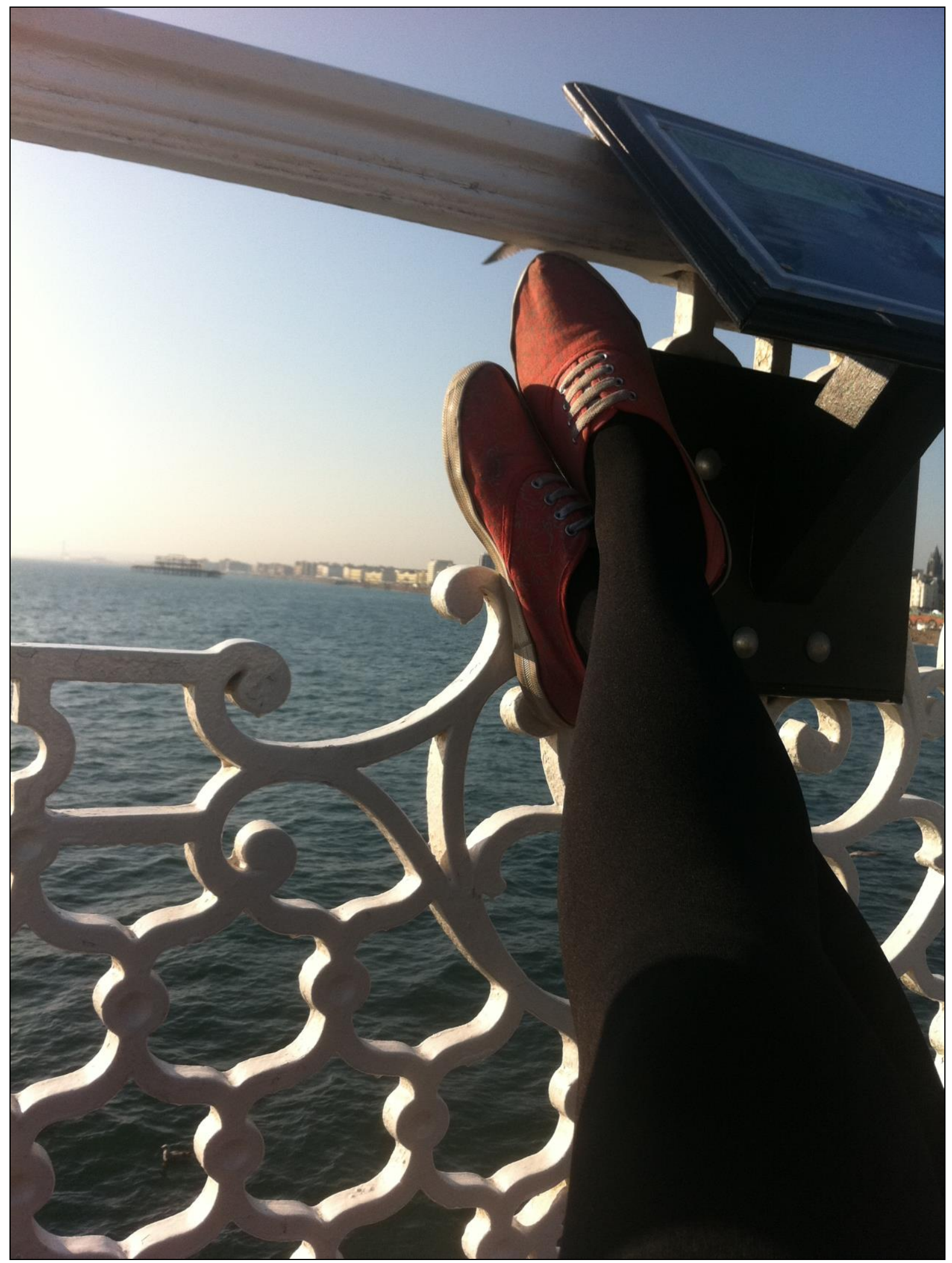

Photo credit: Isabelle Sutton

This work is licensed under a Creative Commons Attribution 3.0 License 
TranscUlturAl, vol. 8.1 (2016), 113-120.

http://ejournals.library.ualberta.ca/index.php/TC

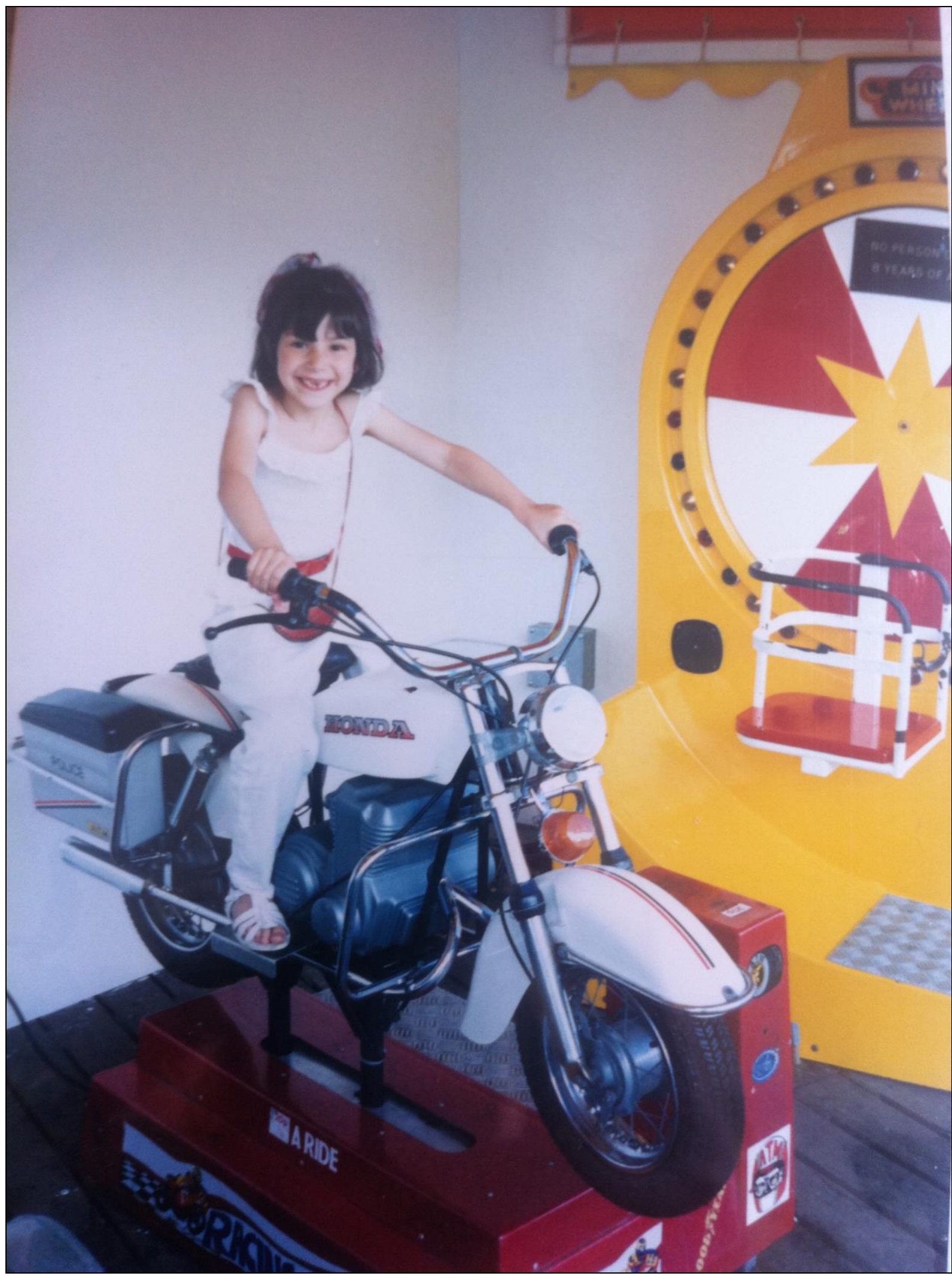

Photo credit: Annie Zeitoun

This work is licensed under a Creative Commons Attribution 3.0 License 


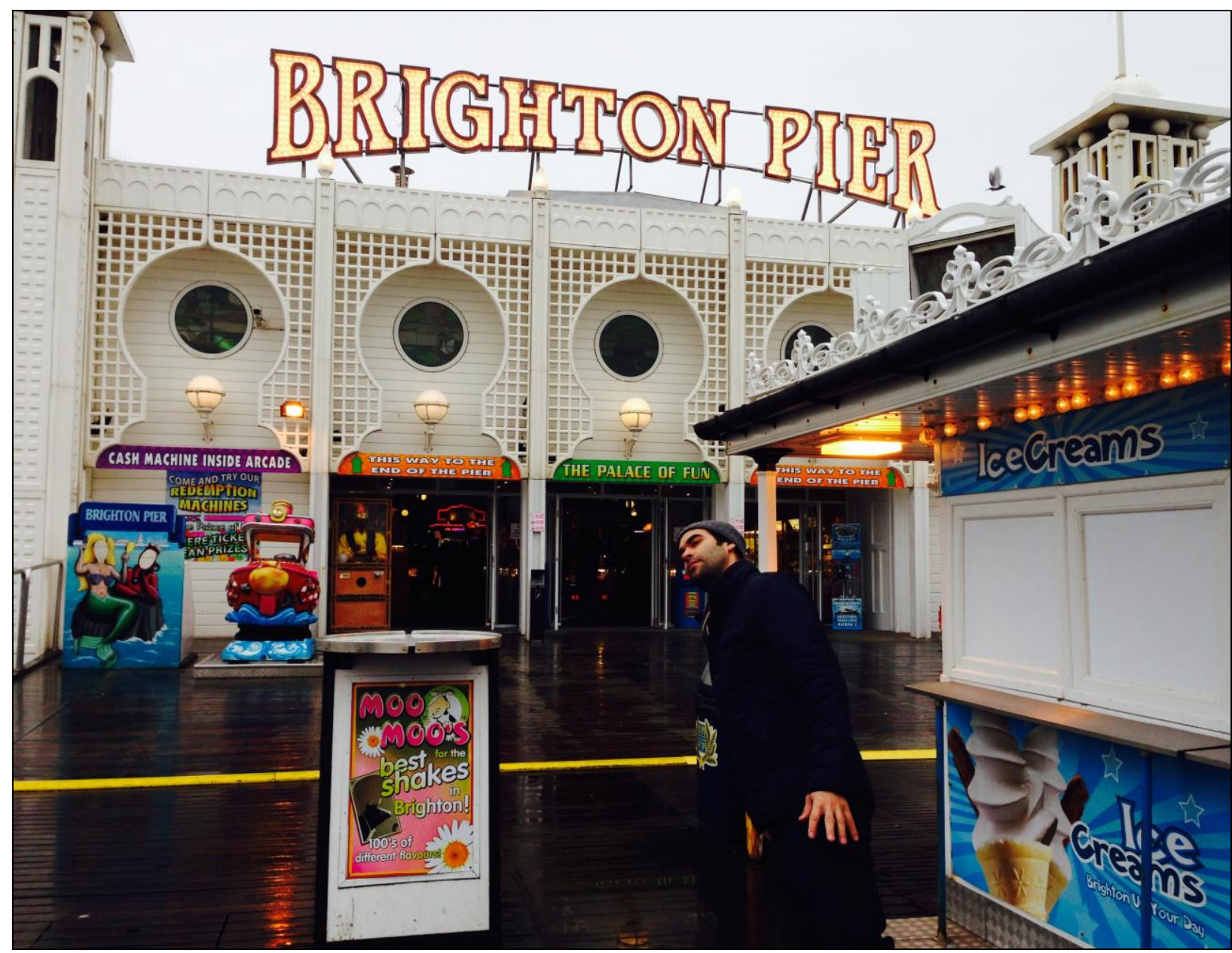

Photo credit: Isabelle Sutton

The Brighton Pier. Although it represents everything touristy about Brighton, it is a place I have to visit every time I am in town. There is something different each time, yet it never changes. The white bars holding my feet up are the same that held me up as a 5-year-old, the same day I rode that motorcycle ride. I love taking people to the Pier when they come to visit. My boyfriend was dragged there on a typical rainy day and listened as I revisited old memories. Now he is the one that is always asking to go back. 
TranscUlturAl, vol. 8.1 (2016), 113-120.

http://ejournals.library.ualberta.ca/index.php/TC

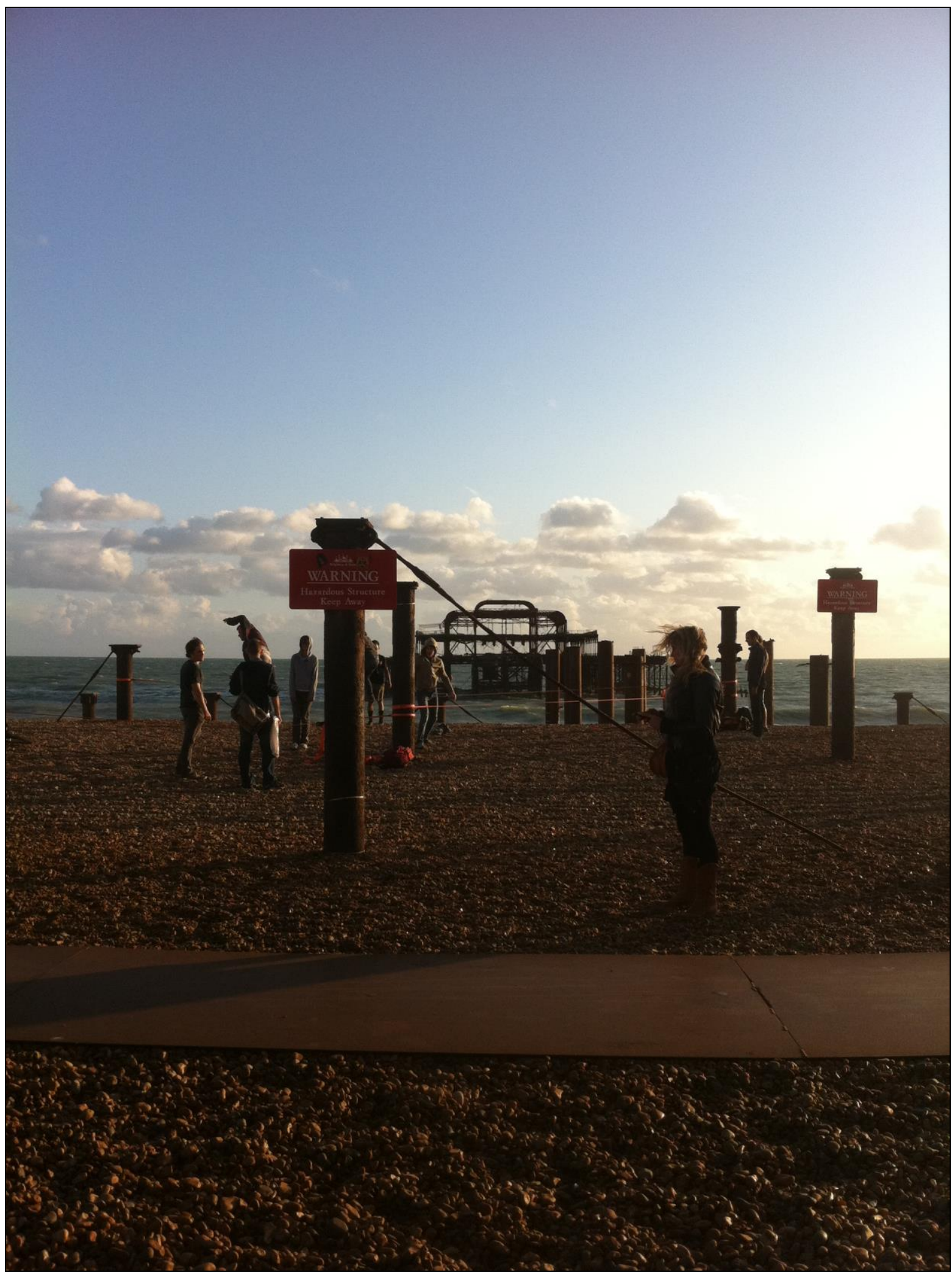

Photo credit: Isabelle Sutton 
Further West from the Brighton Pier is the West Pier. It closed down in the mid 70s after a part of the structure collapsed. It suffered more hardship over the years, due to fires, storms etc. The picture shows what remains of the West Pier today. It seems that each time I go back to Brighton, the remaining structure is getting smaller and smaller, as if it were enduring a long and slow death. There is a sense of melancholy attached to it, but I somehow like the idea of going back over the years and more of it disappearing each time, kind of like memory slowly fading. The remaining structure is important in a way, and it will be a sad day when the West Pier is gone.

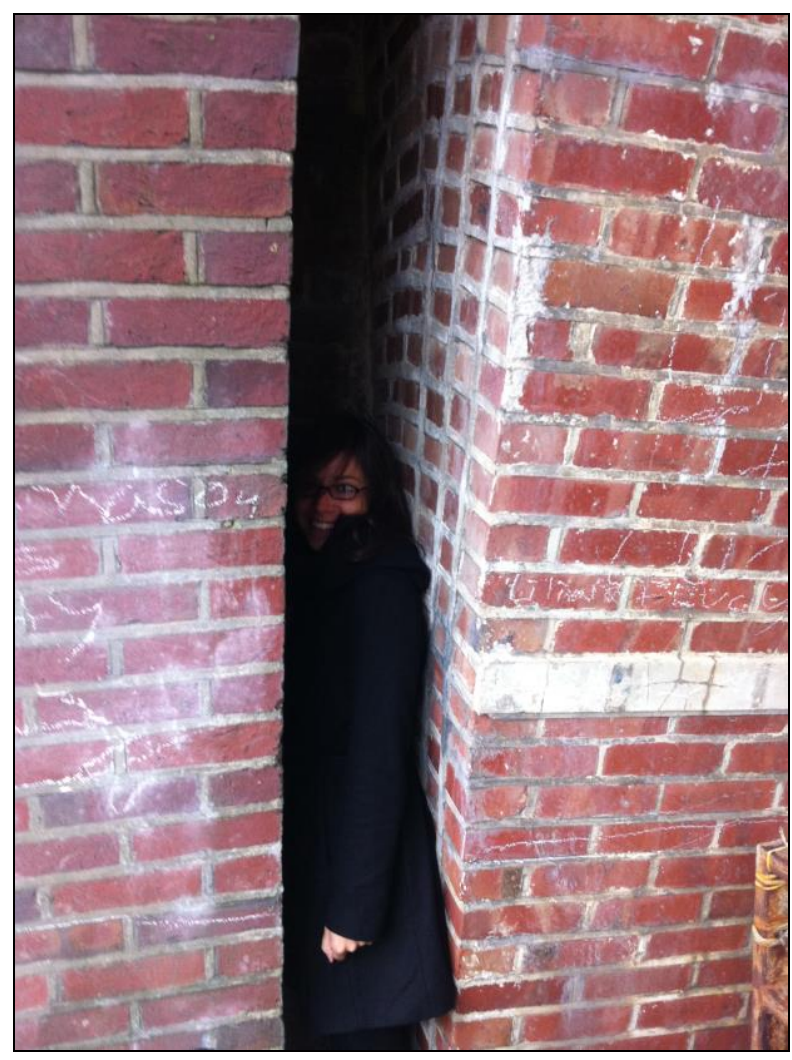

Photo credit: Peter Sutton

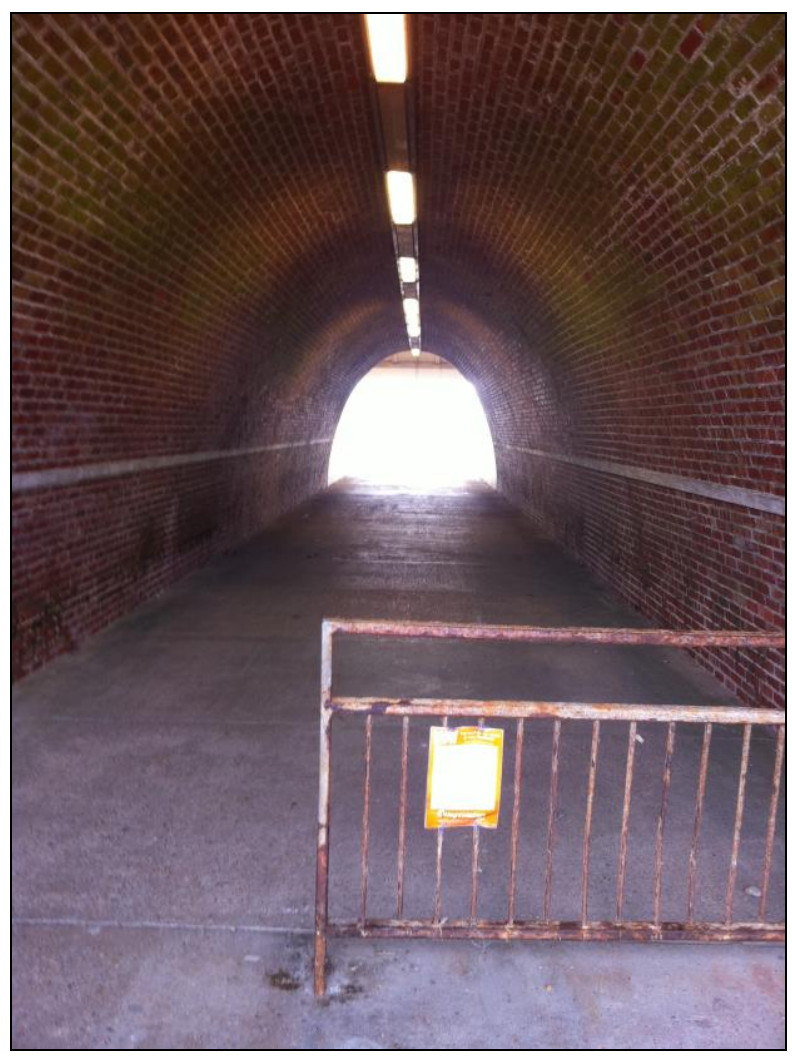

Photo credit: Isabelle Sutton

Saltdean is a small coastal town just outside of Brighton. We used to go there regularly on little day trips on the weekend and still do to this day. To get to the beach, you have to walk down this tunnel. At the entrance of the tunnel there is this little gap in the wall where one of us would always go hide as kids to scare the rest of the family. This is something we still do today (as seen on the photo!), although the gap in the wall seems to be getting smaller and smaller and the long tunnel does not seem as long or scary anymore. The photo of my little sister and me on Brighton beach was taken almost 20 years ago. It truly captures a moment, one that is very representative of all the memories I have from my hometown. 
TranscUlturAl, vol. 8.1 (2016), 113-120.

http://ejournals.library.ualberta.ca/index.php/TC

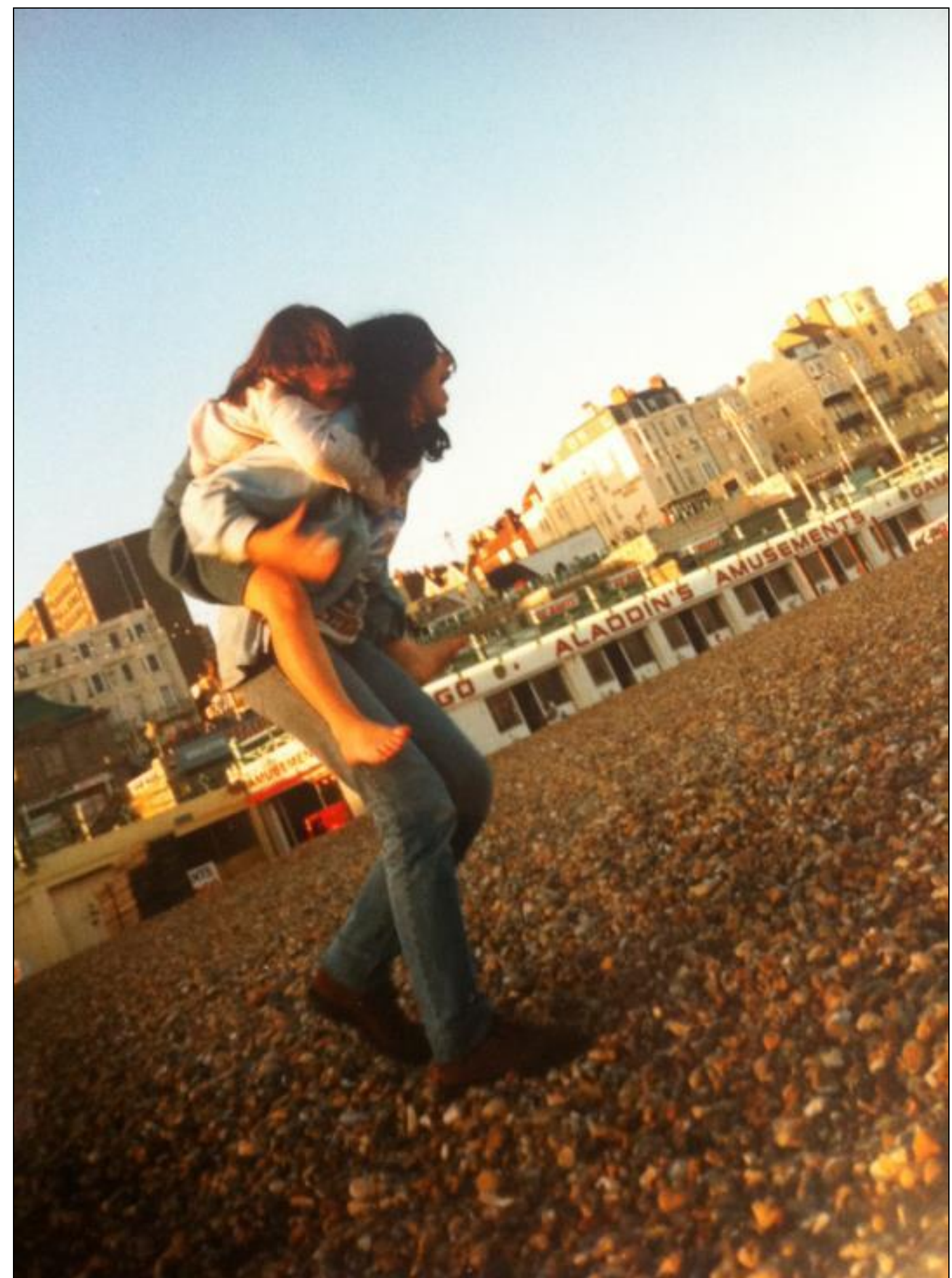

Photo credit: Peter Sutton

This work is licensed under a Creative Commons Attribution 3.0 License 